\title{
Pre-grouting for Leakage Control and Rock Improvement
}

Subash TR, Abhilash Urs KR, Ananth $\mathbf{M}^{*}$ and Tamilselvan $\mathrm{K}$

L\&T Construction, Chennai, India

\begin{abstract}
In underground construction, ground water inflow and rock mass stability has been a challenging problem. Especially the tunnels constructed below ground water table are often exposed to risk of ground water inflow. Protection of underground structures against water ingress and rock mass failure is of paramount importance during construction as well as operation of the tunnel. Risks associated with these hydrogeological issues often pose challenge to tunneling engineers. Mitigation of these risks by means of pragmatic measures such as pre-grouting can improve the rock mass strength and restrict the water ingress to acceptable levels. The primary purpose of pre-grouting is to improve the rock mass strength and establish an impervious zone around the tunnel periphery, thus leading to reduced support system and permeability of rock mass. The aim of this article is to discuss the concept of pre-grouting as an effective mitigation measure for leakage control and rock mass improvement which is being successfully implemented in many countries.
\end{abstract}

Keywords: Pre-grouting; Permeability; Rock mass stability; Tunnels

\section{Introduction}

Control of groundwater leakage and rock mass stability has always been a challenging task for tunneling engineers. Slowing down of the tunnel advance rates, installation of support systems, durability of the lining systems and hindrance to safe operation of the tunnel are some of the key risks faced in most of tunneling projects due to water ingress and rock mass instability. These problems often lead to schedule delays and cost overruns. Envisaging the magnitude of these highly variable risks and developing appropriate measures to mitigate these risks is the key to successful construction of a tunnel. General perception is to consider grouting as a contingency measure, but pre-grouting has been successfully adopted in many countries to mitigate the aforementioned risks beforehand. A properly planned pre-grouting approach can improve the rock mass strength and establish an impermeable zone around the tunnel periphery [1]. The recent development in grouting materials and grouting technology are increasing the possibility to achieve tangible improvements (impermeability and strengthening) in rock quality by pre-grouting [2]. This article presents some guidelines on pre-grouting methodology, material selection, concept of leakage control and rock mass improvement with illustrations.

\section{A conceptual explanation of grouting}

Pre-Grouting is a process of injecting grout material into boreholes drilled into the rock mass around an excavation, with the purpose of sealing any fissures or joints that intersect the borehole. Thus, pregrouting results in a less permeable and more stable rock mass around the excavation. The main objective of the pre-grouting is

- To enhance the rock mass strength thus leading to reduced support system and increased productivity.

- To reduce the rock mass permeability and thereby control the water leakage to the acceptable levels.

\section{Permissible leakage rate}

The intensity of leakage into a tunnel depends on factors such as permeability of the surrounding rock mass, permeability of the tunnel lining, and groundwater conditions [3]. The permissible leakage rates along a cavern or tunnel alignment system must be decided prior to the excavation phase by considering the actual circumstances into account. Permissible leakage rate for tunnels are often fixed by the owner for the safe operation of a particular tunnel. International standards have been established for the specification of permissible leakage rates. A compendium of permissible leakage rates is tabulated below [4].

\section{Pre-grouting pattern}

In underground projects detailed hydrogeological assessment is implemented prior to arriving at a feasible pre-grouting pattern. Probe and grout hole orientations are often selected and further optimized to cross as many of the rock fractures as possible. Holes should be orientated to intercept rock fractures of greatest potential of impact to the tunnel and at angles which are near normal as possible to the feature's strike and dip. Generally grout hole of spacing $1 \mathrm{~m}$ to $1.5 \mathrm{~m}$ with angle of 4 to 7 degree and length of $15 \mathrm{~m}$ to $25 \mathrm{~m}$ is adopted [5].

\section{Pre-grouting strategy}

A balanced approach to pre-grouting has the potential to reduce the ground water inflow substantially. Strategy for pre-grouting as per Asting is explained below [6].

1. A predetermined number of probe holes are drilled ahead of the tunnel face.

2. A water loss test is carried out by water pressurizing of the holes.

3. The water losses are expressed in terms of Lugeon (L). The measurements give an indication of the water tightness of the rock and are taken into account for determination on the type of grout material that shall be used.

4. The probe holes are grouted until a predetermined counter pressure is achieved.

5. If leakages as measured in the probe holes are greater than acceptable, a new round of control holes between the first ones is drilled. Water losses are measured and grouting is carried out according to the same criteria as for the probe holes.

6. The procedure is repeated until the criteria for water tightness are fulfilled.

*Corresponding author: Ananth M, L\&T Construction, Chennai, India, Tel: +919566913277; E-mail: ananthm@Intecc.com

Received April 11, 2016; Accepted April 26, 2016; Published April 28, 2016

Citation: Subash TR, Abhilash Urs KR, Ananth M, Tamilselvan K (2016) Pregrouting for Leakage Control and Rock Improvement. J Civil Environ Eng 6: 226 doi:10.4172/2165-784X.1000226

Copyright: (c) 2016 Subash TR, et al. This is an open-access article distributed under the terms of the Creative Commons Attribution License, which permits unrestricted use, distribution, and reproduction in any medium, provided the original author and source are credited. 


\section{Execution of pre-grouting}

Pre-grouting is generally either done from the surface or from inside the tunnel. The method of drilling and injection of grout depends on the site conditions. In untreated rock, partial hole collapse and difficulty in retraction of drilling rods is a possibility. For this reason, one of the practices is to establish the drill holes through pipes grouted up to a certain extent. A gist of generic grouting methodology is summarized below [7] (Figure 1).

1. Drilling of $40-75 \mathrm{~mm}$ diameter hole to required length and inclination as per the site condition. The pattern and spacing of the grout holes will be based on groutability test.

2. Installation of a pipe with internal diameter to fit the expandable packers.

3. Placement of packer at the very end of the pipe and injection of a cement based grout which fills the annular space between the rock and the pipe. Hardening for about 12 hours.

4. When the grout is hardened, drilling through the pipe to feasible length.

5. Placement of packer and pressure injection with appropriate cement grout for penetration into the rock mass in the drilled length of the hole. Termination criteria as per grout mix design.

6. After hardening of the injected grout, re-drilling through the pipe and injected area to design length beyond last drilled length.

7. Placement of the packer in the pipe and inject (repetition of step 5).

\section{Grout materials}

The selection of grout material is an essential part of grouting. The grout must have the ability to penetrate the fractures to seal them [8]. The selection of appropriate grout material depends on the size, frequency and configuration of the fractures and pores in the rock mass. The particle size of the cementitious material plays a key role in the selection criteria of grout. Based on the fissures size in the rock mass, grout material will be selected. Many methods such as Mercury injection, Gas expansion, Optical method and X-ray tomography methods have been developed for determining fissure size/porosity in rock mass samples.

This paper primarily focuses on cementitious grouts and hence the same has been elaborated below.

Cement: Generally to achieve the cost effectiveness, stable grouts formulated with locally available ordinary Portland cement is used. This cement has an average particle size of $45 \mu \mathrm{m}$ and fineness of about $225 \mathrm{~m}^{2} / \mathrm{kg}$. Micro-cement is used for finer fissures, where it is not feasible to use OPC. Micro-cement is finely grounded ordinary cement with large specific surface and fine particle size of about $15 \mu \mathrm{m}$. As an alternative to cement-based materials, various solutions have been evaluated as grouting materials such as colloidal silica. Colloidal silica is an aqueous dispersion of discrete colloidal amorphous silica particles. The particle size of the colloidal silica is less than $0.015 \mu \mathrm{m}$. A schematic illustration of different cement particles $(\mu \mathrm{m})$ with respect to rock aperture is portrayed in Figure 2.

As a general rule of thumb the type of cement can be chosen based on the groutability ratio. The groutability ratio for rock depends on width of the crack and the grain size of the grout material, expressed as shown in the formula below. For groutability ratios $>5$, grouting is considered consistently possible whereas for groutability ratios $<2$, grouting is not considered possible [9].

$$
\text { Groutability Ratio }=\frac{\text { Width of Fissure }}{\mathrm{D}_{95} \text { of Grout }}
$$

Water cement ratio: The properties of cement-based grouts vary with respect to w/c ratio. Generally for the grout $\mathrm{mix}, \mathrm{w} / \mathrm{c}$ ratio starts at $3: 1$ and is gradually thickened to $2: 1,1: 1$ and $0.5: 1$ until refusal is reached.

\section{Additives}

Different additives can be used to change the properties of the grout. The most common are superplasticizers, which are used to increase the flowability of the grout and to improve dispersion. Other additives are accelerators, non-shrink and thixotropic admixtures.

\section{Pre-grouting - leakage control}

The rock mass is a discontinuous material and its hydraulic characteristics vary widely from an impervious medium to a highly conductive zone. Permeability of rock mass is defined as the ability of a rock to allow the passage of water through its pores, fissure and joint. Generally, the amount of water flowing through a certain area can be represented by the coefficient of permeability. For rock mass, the coefficient of permeability is a function of rock type, pore size,

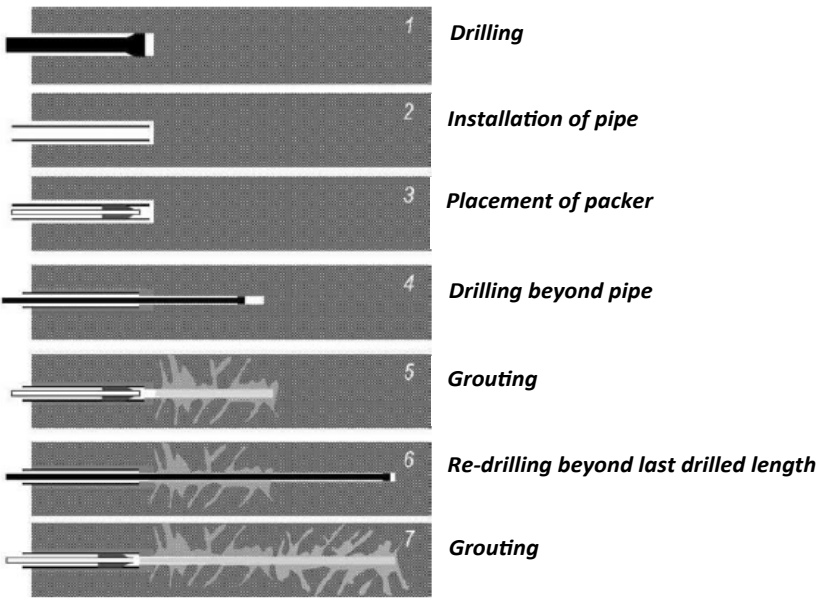

Figure 1: Pre-grouting methodology.

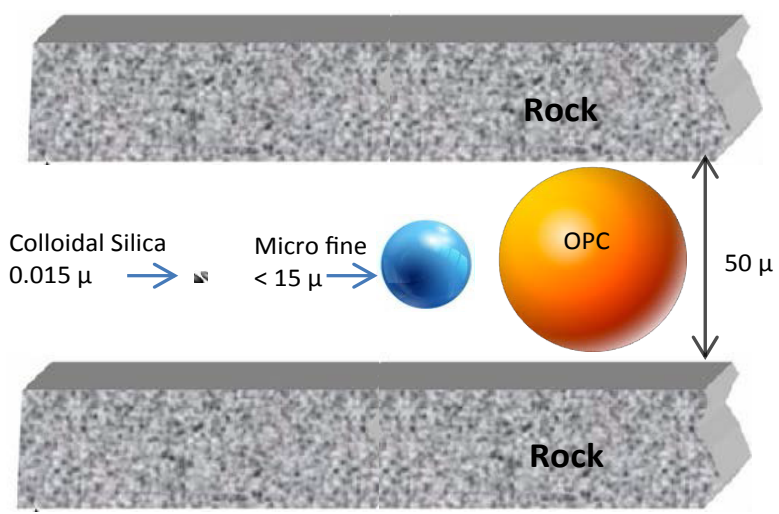

Figure 2: Particle size distribution 
entrapped air in the pores, rock temperature, and viscosity of water (Table 1).

The primary purpose of a pre-grouting scheme is to establish an impervious zone around the tunnel periphery, where the hydraulic conductivity is reduced. This zone ensures that the all-round hydrostatic pressure surrounding the tunnel is distanced from the tunnel periphery to the outskirts of the pre-grouted zone as depicted in Figure 3 [10]. The water pressure is gradually reduced through the grouted zone and the water pressure acting on the tunnel lining can be close to nil. Studies conducted in Norway suggest that, tunneling in urban areas may be subject to a maximum allowable water inflow level of 2-4 liters per minute per 100 meter tunnel, whilst in remote areas such as subsea tunnels the maximum allowable level can be fixed to 30 litres per minute per 100 meters. Table 2 below illustrates the reduction in ground water inflow due to pre-grouting in few of the Norwegian tunneling projects [11].

\begin{tabular}{|c|c|c|c|}
\hline \multirow{2}{*}{ Standards } & \multicolumn{3}{|c|}{ Moisture Characteristics } \\
\cline { 2 - 4 } & Completely Dry & Largely Dry & $\begin{array}{c}\text { Capillary } \\
\text { penetration }\end{array}$ \\
\hline $\begin{array}{c}\text { ITA tech REPORT- } \\
2013\end{array}$ & Nil Discharge (litre/sq.m/day) \\
\hline $\begin{array}{c}\text { German Rail AITES } \\
\text { - 2001 }\end{array}$ & Nil & $0.0199(<0.02)$ & 0.02 \\
\hline Haack -1991 & 0.01 & 0.05 & 0.1 \\
\hline ITA REPORT- 1991 & 0.001 & 0.05 & 0.1 \\
\hline $\begin{array}{l}\text { Note: Description of } \\
\text { corresponding references. }\end{array}$ & 0.1 & 0.1 \\
\hline
\end{tabular}

Table 1: Permissible leakage rates as per International standards.

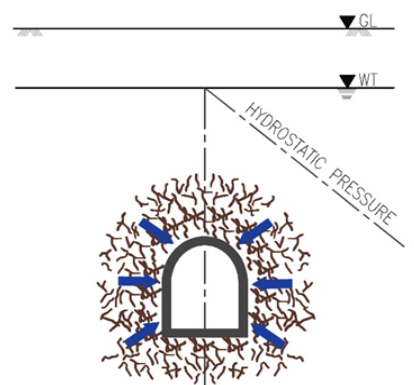

(a)

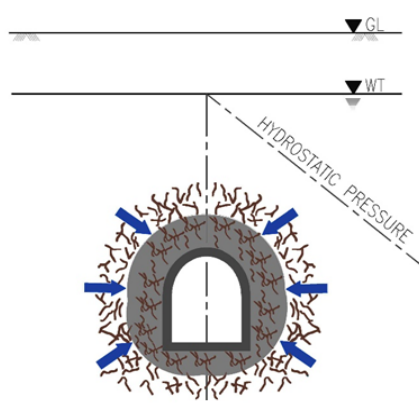

(b)
Figure 3: Hydrostatic pressure (a) Before pre-grouting (b) After pre-grouting.

\begin{tabular}{|c|c|c|c|c|}
\hline \multirow{2}{*}{ Projects } & \multirow{2}{*}{ Depth (m) } & Requirement & Result & \multirow{2}{*}{ Materials } \\
\hline & & \multicolumn{2}{|c|}{$(1 / \mathrm{min} / 100 \mathrm{~m})$} & \\
\hline Baneheia & $20-40$ & $6-12$ & 1.8 & $\begin{array}{l}\text { Micro cement with micro } \\
\text { silica }\end{array}$ \\
\hline Storhaug & $10-15$ & 3 & 1.6 & $\begin{array}{l}\text { Micro cement with micro } \\
\text { silica }\end{array}$ \\
\hline Metro in Osla & $20-25$ & $7-14$ & $3-8$ & $\begin{array}{l}\text { Micro cement with micro } \\
\text { silica }\end{array}$ \\
\hline Froya & 150 & 30 & 12 & $\begin{array}{l}\text { Standard cement with } \\
\text { micro cement }\end{array}$ \\
\hline Lunner & $10-300$ & $10-20$ & 8 & $\begin{array}{l}\text { Standard cement with } \\
\text { micro cement }\end{array}$ \\
\hline Bragarness & $10-150$ & $10-30$ & 10 & $\begin{array}{l}\text { Standard cement with } \\
\text { micro silica }\end{array}$ \\
\hline Hagan & $6-60$ & $5-10$ & $4-19$ & $\begin{array}{l}\text { Standard cement with } \\
\text { micro silica }\end{array}$ \\
\hline
\end{tabular}

Table 2: Reduction in ground water inflow due to pre-grouting in tunnel projects.
Barton observed that pre-grouting reduces the maximum permeability by 17 times and the minimum permeability by one-tenth in rock mass. Neby have noted that for a water treatment plant at Oslo, water leakage at tunnel face reduced from 100 liters/min to 27 liters/ min due to pre-grouting.

\section{Pre-grouting - rock improvement}

Barton considered a $10 \mathrm{~m}$ diameter tunnel in quartzite rock with UCS of $50 \mathrm{MPa}$ under $200 \mathrm{~m}$ overburden to witness the effect of pregrouting by analysing various engineering parameters before and after pre-grouting. Improvement in some of the key rock mass parameters is shown in Table 3.

Thus, with these rock mass parameters, Singh and Goel noted an improvement in about 25 engineering parameters by the implementation of pre-grouting, notable few are depicted in Figure 4. A typical calculation for improvement in rock mass quality and reduction in permeability due to pre-grouting is illustrated below

$$
\begin{aligned}
& \text { Rock Mass Quality, } \mathrm{Q}=\frac{\mathrm{RQD}}{\mathrm{J}_{\mathrm{n}}} \times \frac{\mathrm{J}_{\mathrm{r}}}{\mathrm{J}_{\mathrm{a}}} \times \frac{\mathrm{J}_{\mathrm{w}}}{\mathrm{SRF}} \\
& \mathrm{Q}=\frac{30}{9} \times \frac{1}{2} \times \frac{0.5}{1}=0.83 \\
& \mathrm{Q}=\frac{50}{6} \times \frac{2}{1} \times \frac{1}{1}=16.7 \\
& \text { Permeability, } \mathrm{k}=\frac{0.002}{\mathrm{Q}} \times \frac{100}{\mathrm{JCS}} \times \frac{1}{\mathrm{H}^{5 / 3}} \\
& \mathrm{k}=\frac{0.002}{0.83} \times \frac{100}{50} \times \frac{1}{200^{5 / 3}}=7 \times 10^{-7} \mathrm{~m} / \mathrm{sec} \quad \text { [Before Pre-grouting] } \\
& \mathrm{k}=\frac{0.002}{16.7} \times \frac{100}{50} \times \frac{1}{200^{5 / 3}}=3.5 \times 10^{-8} \mathrm{~m} / \mathrm{sec} \quad \text { [After Pre-grouting] }
\end{aligned}
$$

High Q-values indicates good stability and low values means poor stability. Quality of rock mass increased from 0.83 to 16.7 with the implementation of pre-grouting as seen from the calculation above. Pre-grouting enhances the rock mass strength, thereby reducing the deformation and support pressure, leading to an economical support system. As per Barton model, for the example case discussed earlier the thickness of SFRS and spacing of rock bolts reduces from $100 \mathrm{~mm}$ to none and $1.6 \mathrm{~m}$ to $2.4 \mathrm{~m} \mathrm{c} / \mathrm{c}$ respectively.

\section{Conclusion}

In this article, an effort has been made to showcase pre-grouting as an effective mitigation measure for leakage control and rock mass stability. Some of the noteworthy points pertaining to pre-grouting are mentioned below.

1. It has been noted that permeability can be reduced up to 1 lugeon using cement grout. Also, with the recent developments in grout materials, achieving permeability close to 0.1 Lugeon is possible.

2. Also, Barton observed that pre-grouting reduces the maximum permeability by 17 times and the minimum permeability by one-tenth in rock mass.

3. Neby have noted that for a water treatment plant at Oslo, water leakage at tunnel face reduced from 100 liters/min to 27 liters/ min due to pre-grouting. 


\begin{tabular}{|c|c|c|}
\hline Parameters & Before Grouting & After Grouting \\
\hline Rock Quality Designation, RQD (\%) & 30 & 50 \\
\hline Joint set number, $\mathrm{J}_{\mathrm{n}}$ & 9 & 6 \\
\hline Joint roughness number, $\mathrm{J}_{\mathrm{r}}$ & 1 & 2 \\
\hline Joint alteration number, $\mathrm{J}_{\mathrm{a}}$ & 2 & 1 \\
\hline Joint water reduction factor, $\mathrm{J}_{\mathrm{w}}$ & 0.5 & 1 \\
\hline Stress reduction factor, SRF & 1 & 1 \\
\hline
\end{tabular}

Table 3: Rock mass parameters before and after pre-grouting.

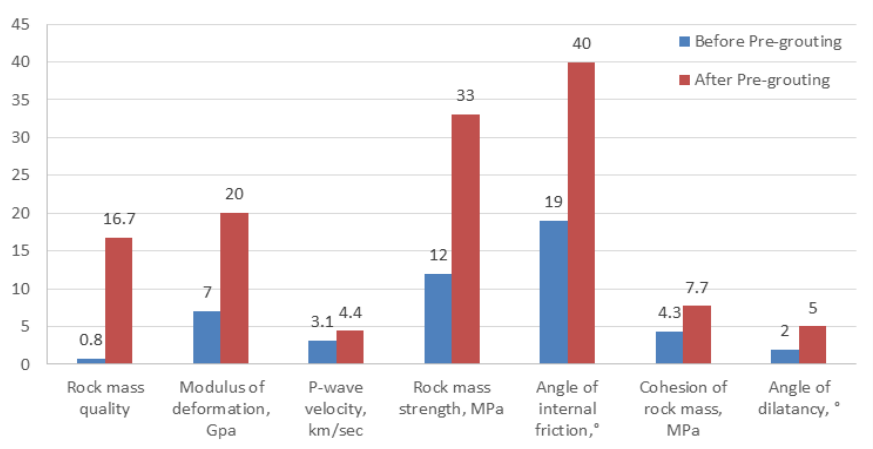

Figure 4: Improvement in rock mass parameters after pre-grouting.

4. As evidenced above, the pre-grouting effectively shifts the hydrostatic pressure from the tunnel periphery to the outskirts of the pre-grouted zone. Thus, pre-grouting can be considered to provide an effective leakage control mechanism.

5. Q value in one case has been improved from 0.8 to 16.7 because of pre-grouting; this indicates that the rock mass category has changed from 'very poor' to 'good'.
6. Singh and Goel observed improvement in 25 rock parameters such as rock mass strength, modulus of deformation and support pressure reduction.

\section{References}

1. Beck and Thomas (2014) Flexible rock supports application and methods Norwegian Tunneling Technol 23: 87-96.

2. Steinar R, Nick B, Tarald N (2001) Grouting - The third leg of underground construction. Norwegian Tunneling Soc 12: 75-80.

3. Alex Nazarchuk PE (2008) Water intrusion in underground structures Massachusetts Institute of Technology, Boston, USA

4. ITAtech design guidance for spray applied waterproofing membranes (2013) ITAtech Activity Group Lining and Waterproofing, ITAtech report N2.

5. Tunnel construction guidelines (2009) Guidance note on pre excavation grouting for underground construction in hard rock - Principles \& design elements. Association of Geotechnical \& Geo-environmental Specialist, Hong Kong.

6. Gunnar A (1983) Experiences with pre-grouting in sewage tunnels in the Oslo Area. Norwegian Tunneling Technol 2: 64-71.

7. Bahadur AK, Holter KG, Pengelly A (2007) Cost-effective pre-injection with rapid hardening micro cement and colloidal silica for water ingress reduction and stabilization of adverse conditions in a headrace tunnel. Underground space - the $4^{\text {th }}$ Dimension of Metropolises, London, 297-301.

8. Ann E, Martin M, Gunnar H (2007) Rock grouting, current competence and development for the final repository, SKB Rapport R-07-30.

9. Koronakis N, Kontothanassis P, Katsaris D, Bournazos J (2005) Design of water isolation grouting for reducing high water inflows in urban shallow tunnels, Taylor \& Francis Group plc, London, UK, 271-276.

10. Maidl B, Thewes M, Maidl U (2013) Handbook of Tunnel Engineering II, Basics and additional services for design and construction. Wilhelm Ernst \& Sohn publications, Germany.

11. Bhawani S, Goel RK (2011) Engineering rock mass classification, tunneling foundations, and landslides. Butterworth-Heinemann publications, Elsevier, USA. 